\title{
Author Correction: Ionic shape-morphing microrobotic end-effectors for environmentally adaptive targeting, releasing, and sampling
}

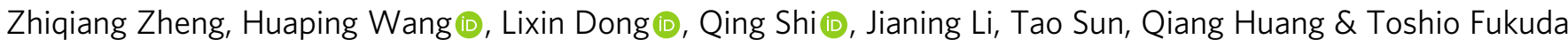

Correction to: Nature Communications https://doi.org/10.1038/s41467-020-20697-w, published online 18 January 2021.

The original version of this Article contained an error in the author affiliations.

Lixin Dong was incorrectly associated with 'Beijing Advanced Innovation Center for Intelligent Robots and Systems, Beijing Institute of Technology, 100081 Beijing, China.' instead of the correct 'Department of Biomedical Engineering, City University of Hong Kong, 999077 Hong Kong, China'.

In addition, the following statement was omitted from the 'Acknowledgement' section:

'L.D. thanks the Beijing Institute of Technology for hosting him as a visiting professor prior to join the City University of Hong Kong, which has enabled this collaborative work'.

These errors have now been corrected in both the PDF and HTML versions of the article.

Published online: 05 March 2021

(c) Open Access This article is licensed under a Creative Commons Attribution 4.0 International License, which permits use, sharing, adaptation, distribution and reproduction in any medium or format, as long as you give appropriate credit to the original author(s) and the source, provide a link to the Creative Commons license, and indicate if changes were made. The images or other third party material in this article are included in the article's Creative Commons license, unless indicated otherwise in a credit line to the material. If material is not included in the article's Creative Commons license and your intended use is not permitted by statutory regulation or exceeds the permitted use, you will need to obtain permission directly from the copyright holder. To view a copy of this license, visit http://creativecommons.org/licenses/by/4.0/.

(C) The Author(s) 2021 